\title{
Practice Trends in the Surgical Management of Renal Tumors in an Academic Medical Center in the Past Decade
}

\author{
Matheus Tannus, ${ }^{1,2}$ Fábio Sepúlveda, ${ }^{1}$ Thomé Pinheiro, ${ }^{1}$ and Cássio Andreoni ${ }^{1}$ \\ ${ }^{1}$ Division of Urology, Federal University of Sao Paulo, Sao Paulo, SP, Brazil \\ ${ }^{2}$ R. Alexandrina Ramalho, 70 apt 904, Salvador-BA, 40296230, Brazil
}

Correspondence should be addressed to Matheus Tannus; matheustannus@hotmail.com

Received 18 February 2013; Accepted 18 March 2013

Academic Editors: A. Mahajna, H. Sarel, and C. Schwentner

Copyright (C) 2013 Matheus Tannus et al. This is an open access article distributed under the Creative Commons Attribution License, which permits unrestricted use, distribution, and reproduction in any medium, provided the original work is properly cited.

\begin{abstract}
Objectives. To evaluate the trends of surgical treatment of the renal tumor in an academic medical center. Methods. Between 2001 and 2010, 505 were treated surgically at the Federal University of Sao Paulo for renal tumors. The following variables were observed and analyzed according to their evolution through time: frequency and types of surgeries performed, operative time, hospital stay, and warm ischemia time for partial nephrectomy. Results. An increase in the frequency of laparoscopic radical nephrectomies, open partial nephrectomies, and laparoscopic partial nephrectomies was observed when comparing the periods from 2001 to 2005 $(4.3 \%, 2.6 \%$, and $12.6 \%$, resp.) and from 2006 to 2010 (13.2\%, 18.6\%, and 20.2\%, resp.; $P<0.001)$. The average of operative time, hospital stay, and tumor size diminished (from 211.7 to 177.17 minutes, from 5.52 to 4.22 days, and from 6.72 to $5.29 \mathrm{~cm}$, resp.) when compared to the periods from 2001 to 2005 and from 2006 to $2010(P<0.001, P=0.016, P<0.001$, resp.). Conclusion. As time goes by, there has been a significant reduction in the hospital stay time, surgery time, and size of renal tumor in patients treated surgically. The frequencies of minimally invasive and nephron-sparing surgeries have increased over the last years.
\end{abstract}

\section{Introduction}

Surgery continues to be the main form of treatment for a renal tumor. The renal cell carcinoma (RCC) is the main malignant renal tumor and is one of the most lethal urologic cancers. It includes a number of distinct subtypes derived from the various parts of nephrons, each one with a unique genetic base and tumor biology [1].

The goal of the surgery is to remove the tumor with an adequate surgical margin. In 1969, Robson and colleagues established the radical nephrectomy (RN) as "gold standard" procedure to heal renal tumors [2]. However, studies have demonstrated that patients who undergo $\mathrm{RN}$ have a greater chance of deterioration of the renal function [3]. At present, over $60 \%$ of renal tumors are incidentally diagnosed in ultrasound scans or in computerized tomographies conducted for other reasons [4]. These tumors are smaller and have a lesser chance of developing metastases [5]. More recently, based on knowledge about chronic renal disease [6] allied to improved technology, minimally invasive and nephronsparing surgeries are being increasingly used in smaller renal tumors $[7,8]$.
However, despite the significant amount of scientific papers revealing the advantages of minimally invasive and nephron-sparing surgery, most urologists still perform open and radical nephrectomies, even for small renal tumors [9]. Moreover, inconsistencies have been pointed out in the treatment of small renal tumors by laparoscopists, as many would remove the entire kidney unnecessarily while open surgeons are more likely to perform partial nephrectomy [10].

The purpose of this study is to evaluate the trends of renal tumor surgical treatment in a teaching medical center in the past decade, where there are experts in both laparoscopic and open surgeries, in order to observe whether and when the benefits of minimally invasive and nephron-sparing surgery were incorporated.

\section{Material and Methods}

Between January 2001 and December 2010, all the patients who underwent surgery for renal tumors at the Federal University of São Paulo were entered in a prospective database. A transversal study was performed with data obtained from 


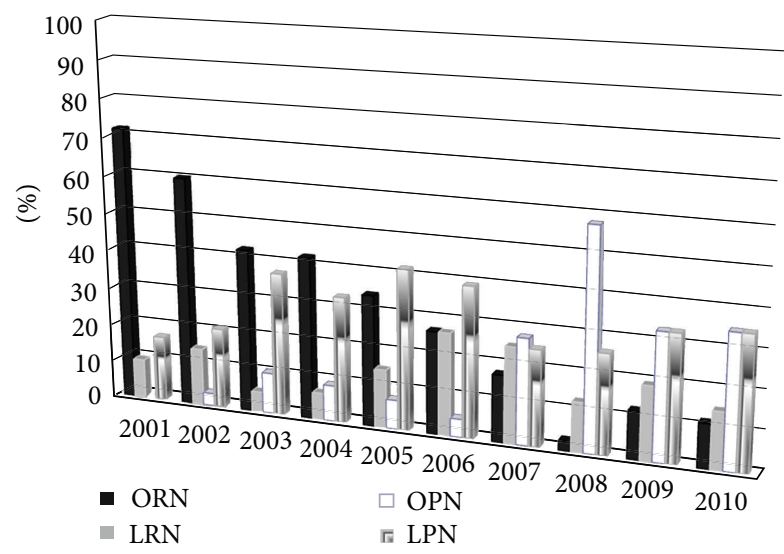

FIGURE 1: Frequency of nephrectomies from 2001 to 2010.

the database and analyzed retrospectively. The preoperatory evaluation included blood and imaging workup.

The types and frequencies of surgeries performed, and histological types of renal tumors diagnosed were observed according to their evolution over time. The data from 2001 to 2005 (number of surgeries, operative time, hospital stay, and warm ischemia time during partial nephrectomies) were compared to the data from 2006 to 2010.

The Mann-Whitney $U$ test was used to evaluate the differences between the variables analyzed. The comparisons between the proportions were done through the Chi-square test $\left(\chi^{2}\right)$. The results were considered statistically significant when the $P$ value was below 5\% $(P<0.05)$. The statistical analysis was performed using PAWS Statistics 17 software.

\section{Results}

Between January 2001 and December 2010, 505 patients were treated surgically for renal tumors. The majority were males (58.6\%). Average age, operative time, hospital stay, and renal tumor size were 56 years (range from 17 to 84 ), $190.3 \mathrm{~min}$ (range from 55 to 630), 4.7 days (range from 1 to 60 ), and $5.9 \mathrm{~cm}$ (range from 0.5 to 28 ), respectively. The most frequent histological subtype was the RCC (74.5\%) followed by the angiomyolipoma (6.9\%). The laparoscopic partial nephrectomy (LPN) was the most performed surgery totaling $32.1 \%$ of all surgical procedures. Right after, the open radical nephrectomy (ORN), the open partial nephrectomy $(\mathrm{OPN})$, and the laparoscopic radical nephrectomy (LRN) came each representing $27.9 \%, 20.8 \%$, and $17 \%$ of surgeries, respectively. Other minimally invasive surgical procedures, such as radiofrequency and cryotherapy, were also utilized but in a minority of patients (1.6\%) (Table 1).

Figure 1 shows the frequency of surgeries per year for the time period of 2001 to 2010, and it reveals a tendency of reduction in the number of ORNs and an increase in the number of LRNs, OPNS, and LPNs, as time passes by. Such an observation was confirmed when we stratified the comparison into period (Table 2). There was a statistically significant reduction $(P<0.001)$ in the frequency of ORNs
TABLE 1: Demographic data and tumor characteristics from January 2001 to December 2010.

\begin{tabular}{lc}
\hline & $N=505$ \\
\hline Mean age (years) & $56(17$ to 84$)$ \\
Male/female & $296(58.6 \%) / 209(41.4 \%)$ \\
Operative time (minutes) & $190.3(55$ to 630$)$ \\
Hospital stay (days) & $4.7(1$ to 60$)$ \\
Tumor size (cm) & $5.9(0.5$ to 28$)$ \\
Type of surgery & \\
Open radical nephrectomy & $141(27.9 \%)$ \\
Laparoscopic radical nephrectomy & $86(17 \%)$ \\
Open partial nephrectomy & $105(20.8 \%)$ \\
Laparoscopic partial nephrectomy & $162(32.1 \%)$ \\
Needle ablation & $11(2.2 \%)$ \\
Histological subtype & \\
Renal cell carcinoma & $376(74.5 \%)$ \\
Angiomyolipoma & $35(6.9 \%)$ \\
Transitional cell carcinoma & $29(5.7 \%)$ \\
Oncocytoma & $20(3.9 \%)$ \\
Benign cyst & $15(2.9 \%)$ \\
Benign adenoma & $5(0.9 \%)$ \\
Others & $25(4.9 \%)$ \\
\hline
\end{tabular}

in the period of 2001 to 2005 (18.8\%) when compared to the period of 2006 to 2010 (9.7\%). Opposing this, an increase in the frequency of LRNs, OPNS, and LPNs was observed when comparing the periods of 2001 to 2005 (4.3\%, 2.6\%, and $12.6 \%$, resp.) to the last five years $(13.2 \%, 18.6 \%$, and $20.2 \%$, resp.), with a statistic significance $(P<0.001)$.

Table 3 shows that when considering the type of surgical procedure (open or laparoscopic), the number was found to be similar (246 open nephrectomies and 248 laparoscopic nephrectomies); however, the average operative time, the hospital stay, and the tumor size were less for laparoscopic procedures when compared to open surgeries revealing a statistical significant difference $(P<0.001$, for all three variables).

\section{Discussion}

The present study reveals that there has been a change on the way that renal tumor surgery has been approached throughout the past ten years. ORN was the most performed surgery (72.4\%) in the year of 2001, whereas in 2010, this same type of surgery had already reached the lowest frequency level among the conducted procedures (11.8\%). In 1963, Robson, from the University of Toronto, made RN to be the main surgery for the treatment of renal tumors due to its excellent oncologic results [2]. However, more recent studies have revealed that patients who underwent $\mathrm{RN}$ presented a greater risk of creatinine high level and of developing proteinuria [11].

During the first years after laparoscopy was introduced into modern surgery, it seemed to be an impossible task conducting a nephrectomy through this method. In 1990, Clayman from the Washington University School of Medicine 
TABLE 2: Number and proportion of nephrectomies from 2001 to 2005 and from 2006 to 2010.

\begin{tabular}{lcccc}
\hline Date & $\begin{array}{c}\text { Open radical nephrectomy } \\
(\%)\end{array}$ & $\begin{array}{c}\text { Laparoscopic radical } \\
\text { nephrectomy }(\%)\end{array}$ & $\begin{array}{c}\text { Open partial nephrectomy } \\
(\%)\end{array}$ & $\begin{array}{c}\text { Laparoscopic partial } \\
\text { nephrectomy }(\%)\end{array}$ \\
\hline 2001 to 2005 & $93(18.8 \%)$ & $21(4.3 \%)$ & $13(2.6 \%)$ & $62(12.6 \%)$ \\
2006 to 2010 & $48(9.7 \%)$ & $65(13.2 \%)$ & $92(18.6 \%)$ & $100(20.2 \%)$ \\
\hline Total & $141(27.9 \%)$ & $86(17 \%)$ & $105(20.8 \%)$ & $162(32.1 \%)$ \\
\hline
\end{tabular}

$P<0.001$ (Chi-square test).

TABle 3: Number of openand laparoscopic nephrectomies and comparison of the mean operative time, hospital stay, and tumor size between 2001 and 2010 .

\begin{tabular}{lccc}
\hline & $\begin{array}{c}\text { Open } \\
\text { nephrectomies }\end{array}$ & $\begin{array}{c}\text { Laparoscopic } \\
\text { nephrectomies }\end{array}$ & $P$ \\
\hline $\begin{array}{l}\text { Number of surgeries } \\
\begin{array}{l}\text { Operative time } \\
\text { (minutes) }\end{array}\end{array}$ & 246 & 248 & - \\
$\begin{array}{l}\text { Hospital stay (days) } \\
\text { Tumor size (cm) }\end{array}$ & 6.4 & 170.6 & $<0.001$ \\
\hline
\end{tabular}

Mann-Whitney $U$ test.

made a significant contribution to the development of laparoscopic renal surgery, which made it possible to remove the entire kidney from the abdominal cavity through an incision, placing the organ inside an endobag and mincing it through the aid of a motorized morcellator [12]. Subsequent analyses were quick to demonstrate the advantages of laparoscopic procedures compared to open surgery. When compared to classical surgery, the minimally invasive procedures resulted in similar oncological results, reduced blood loss, a smaller quantity of analgesics during postsurgery times, decrease in hospital stay time, and no increase in the risk of postsurgery complications $[13,14]$.

The present series demonstrated a significant reduction in operative time, hospital stay time, and tumor size when comparing laparoscopy to open surgeries between the periods of 2001 to 2005 and 2006 to 2010. These data reveal an important evolution in the feasibility of the laparoscopic procedure.

The nephron-sparing surgery for the treatment of renal tumors was initially described by Czerny in 1890, but the high death rate limited its application during a long-time [15]. Recently, advances in imaging technology, experience obtained in renovascular surgeries due to other conditions, improvement in prevention methods of renal damage by ischemia, increase in the number of low-grade RCCs found incidentally, and the good results obtained in long term patient survival have made the nephron-sparing surgeries to become an excellent alternative for the treatment of small renal masses [16]. The OPN allows for better renal function preservation and similar oncological results to the $\mathrm{RN}$ in selected patients [17]. The LPN has been recently developed and has incorporated the fundamental principles of open surgery [18]. In the last years, nephron-sparing surgeries have gained worldwide acceptance as the method for treating small renal tumors with peripheral location [14]. In many academic

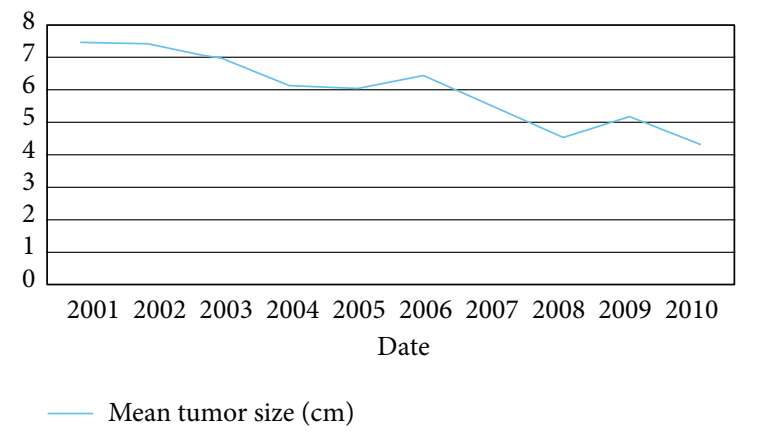

FIGURE 2: Reduction of renal tumor size in the period from 2001 to 2010.

centers, partial nephrectomies today represent $60 \%-70 \%$ of all surgeries conducted for RCC [19].

In our center, ORN has been substituted by minimally invasive and nephron-sparing procedures throughout time. In 2010, partial nephrectomies were already the most frequent surgeries $(72.4 \%)$, being that LPN was the most conducted procedure in the whole period (32.1\%) representing an ascending curve in the last years (Figure 1). When the number of surgeries is compared according to the time period (2001 to 2005 and 2006 to 2010), we observe a reduction in ORNs and an increase for minimally invasive and nephron-sparing surgeries.

The size of the tumor is the main prognostic factor for RCC. This observation results from several publications about this matter [20], which have been encouraging frequent proposals for the change in the staging of the illness [21]. Studies have been demonstrating a significant reduction in the size of tumors during its diagnosis through time [22]. Our data also corroborates this fact, revealing a gradual reduction in the size of tumors with a drop of $41.9 \%$ during the period of 2001 to 2010 (Figure 2). This fact can be justified by the advances in imaging methods which are providing a gradual increase in the so-called "renal incidentalomas." It is well known that tumors found incidentally are smaller and possess a lower risk of malignancy [23]. The reduction in the size of tumors has played an important role in surgical procedures for the preservation of nephrons in the present treatment of renal tumors. In such context, partial nephrectomies play an important role, with a bigger emphasis on LPN, which in dexterous hands has shown better results with respect to OPN in more recent studies [24]. Other therapies, such as active surveillance and ablative techniques, have also surfaced in the face of this new reality in the diagnosis of renal tumors $[25,26]$. 


\section{Conclusions}

There has been a significant reduction in the hospital stay time, operative time, and size of renal tumor in patients treated surgically in the past decade. The frequencies of minimally invasive and nephron-sparing surgeries have increased over the last 10 years.

\section{Abbreviations}

ORN: Open radical nephrectomy

OPN: Open partial nephrectomy

LRN: Laparoscopic radical nephrectomy

LPN: Laparoscopic partial nephrectomy

$\mathrm{RN}$ : Radical nephrectomy

RCC: Renal cell carcinoma.

\section{Conflict of Interests}

The authors declare no conflict of interests.

\section{References}

[1] W. M. Linehan, M. M. Walther, and B. Zbar, "The genetic basis of cancer of the kidney," Journal of Urology, vol. 170, no. 6, pp. 2163-2172, 2003.

[2] C. J. Robson, B. M. Churchill, and W. Anderson, "The results of radical nephrectomy for renal cell carcinoma," Journal of Urology, vol. 101, no. 3, pp. 297-301, 1969.

[3] J. McKiernan, R. Simmons, J. Katz, and P. Russo, "Natural history of chronic renal insufficiency after partial and radical nephrectomy," Urology, vol. 59, no. 6, pp. 816-820, 2002.

[4] N. K. Janzen, H. L. Kim, R. A. Figlin, and A. S. Belldegrun, "Surveillance after radical or partial nephrectomy for localized renal cell carcinoma and management of recurrent disease," Urologic Clinics of North America, vol. 30, no. 4, pp. 843-852, 2003.

[5] J. J. Patard, F. J. Dorey, L. Cindolo et al., "Symptoms as well as tumor size provide prognostic information on patients with localized renal tumors," Journal of Urology, vol. 172, no. 6, pp. 2167-2171, 2004.

[6] W. C. Huang, A. S. Levey, A. M. Serio et al., "Chronic kidney disease after nephrectomy in patients with renal cortical tumours: a retrospective cohort study," Lancet Oncology, vol. 7, no. 9, pp. 735-740, 2006.

[7] R. H. Thompson, S. A. Boorjian, C. M. Lohse et al., "Radical nephrectomy for pTla renal masses may be associated with decreased overall survival compared with partial nephrectomy," Journal of Urology, vol. 179, no. 2, pp. 468-471, 2008.

[8] B. R. Lane and I. S. Gill, "5-year outcomes of laparoscopic partial nephrectomy," Journal of Urology, vol. 177, no. 1, pp. 70-74, 2007.

[9] D. C. Miller, J. M. Hollingsworth, K. S. Hafez, S. Daignault, and B. K. Hollenbeck, "Partial nephrectomy for small renal masses: an emerging quality of care concern?” Journal of Urology, vol. 175, no. 3, pp. 853-857, 2006.

[10] P. Russo, "Evolving strategies for renal tumor surgery: whether by open or by laparoscopic approaches, do the right operation!," Urologic Oncology, vol. 23, no. 6, pp. 456-457, 2005.

[11] J. J. Patard, A. J. Pantuk, M. Crepel et al., "Morbidity and clinical outcome of nephron-sparing surgery in relation to tumor size and indication," European Urology, vol. 52, no. 1, pp. 148-154, 2007.

[12] R. V. Clayman, L. R. Kavoussi, N. J. Soper et al., "Laparoscopic nephrectomy: initial case report," Journal of Urology, vol. 146, no. 2, pp. 278-282, 1991.

[13] D. D. Gaur, D. K. Agarwal, and K. C. Purohit, "Retroperitoneal laparoscopic nephrectomy: initial case report," Journal of Urology, vol. 149, no. 1, pp. 103-105, 1993.

[14] S. Poletajew, A. A. Antoniewicz, and A. Borówka, "Kidney removal the past, presence, and perspectives: a historical review," Urology Journal, vol. 7, no. 4, pp. 215-223, 2010.

[15] H. W. Herr, "A history of partial nephrectomy for renal tumors," Journal of Urology, vol. 173, no. 3, pp. 705-708, 2005.

[16] R. G. Uzzo and A. C. Novick, "Nephron sparing surgery for renal tumors: indications, techniques and outcomes," Journal of Urology, vol. 166, no. 1, pp. 6-18, 2001.

[17] W. K. O. Lau, M. L. Blute, A. L. Weaver, V. E. Torres, and H. Zincke, "Matched comparison of radical nephrectomy versus nephron-sparing surgery in patients with unilateral renal cell carcinoma and a normal contralateral kidney," Mayo Clinic Proceedings, vol. 75, no. 12, pp. 1236-1242, 2000.

[18] I. S. Gill, M. M. Desai, J. H. Kaouk et al., "Laparoscopic partial nephrectomy for renal tumor: duplicating open surgical techniques," Journal of Urology, vol. 167, no. 2 I, pp. 469-475, 2002.

[19] P. Russo and W. Huang, "The medical and oncological rationale for partial nephrectomy for the treatment of T1 renal cortical tumors," Urologic Clinics of North America, vol. 35, no. 4, pp. 635-643, 2008.

[20] J. A. Kontak and S. C. Campbell, "Prognostic factors in renal cell carcinoma," Urologic Clinics of North America, vol. 30, no. 3, pp. 467-480, 2003.

[21] A. Zisman, A. J. Pantuck, D. Chao et al., "Reevaluation of the 1997 TNM classification for renal cell carcinoma: T1 and T2 cutoff point at 4.5 rather than $7 \mathrm{~cm}$. Better correlates with clinical outcome," Journal of Urology, vol. 166, no. 1, pp. 54-58, 2001.

[22] C. T. Lee, J. Katz, W. Shi, H. T. Thaler, V. E. Reuter, and P. Russo, "Surgical management of renal tumors $4 \mathrm{~cm}$. Or less in a contemporary cohort," Journal of Urology, vol. 163, no. 3, pp. 730-736, 2000.

[23] I. Frank, M. L. Blute, J. C. Cheville, C. M. Lohse, A. L. Weaver, and H. Zincke, "Solid renal tumors: an analysis of pathological features related to tumor size," Journal of Urology, vol. 170, no. 6, pp. 2217-2220, 2003.

[24] R. Heuer, I. S. Gill, G. Guazzoni et al., "A critical analysis of the actual role of minimally invasive surgery and active surveillance for kidney cancer," European Urology, vol. 57, no. 2, pp. 223-232, 2010.

[25] R. Abouassaly, B. R. Lane, and A. C. Novick, "Active surveillance of renal masses in elderly patients," Journal of Urology, vol. 180, no. 2, pp. 505-509, 2008.

[26] D. S. Finley, S. Beck, G. Box et al., "Percutaneous and laparoscopic cryoablation of small renal masses," Journal of Urology, vol. 180, no. 2, pp. 492-498, 2008. 


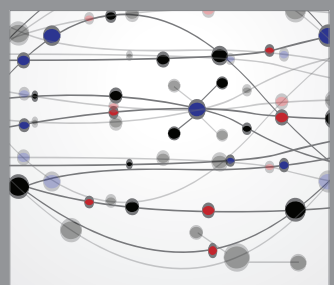

The Scientific World Journal
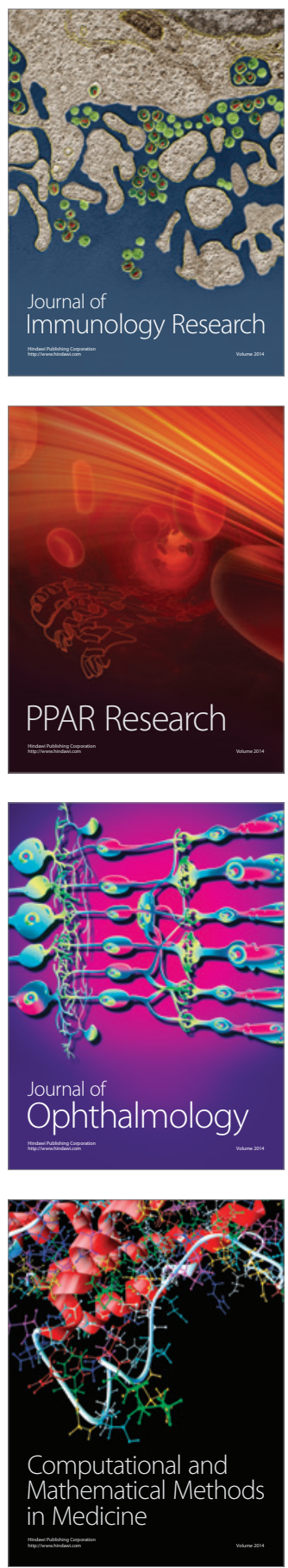

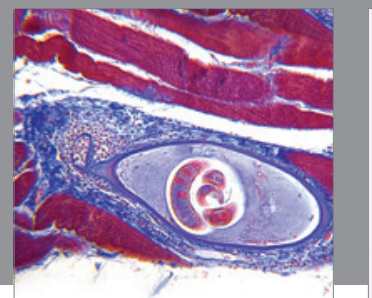

Gastroenterology

Research and Practice
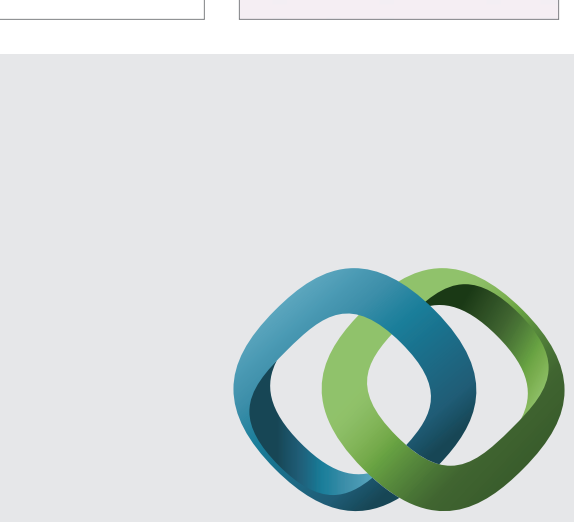

\section{Hindawi}

Submit your manuscripts at

http://www.hindawi.com
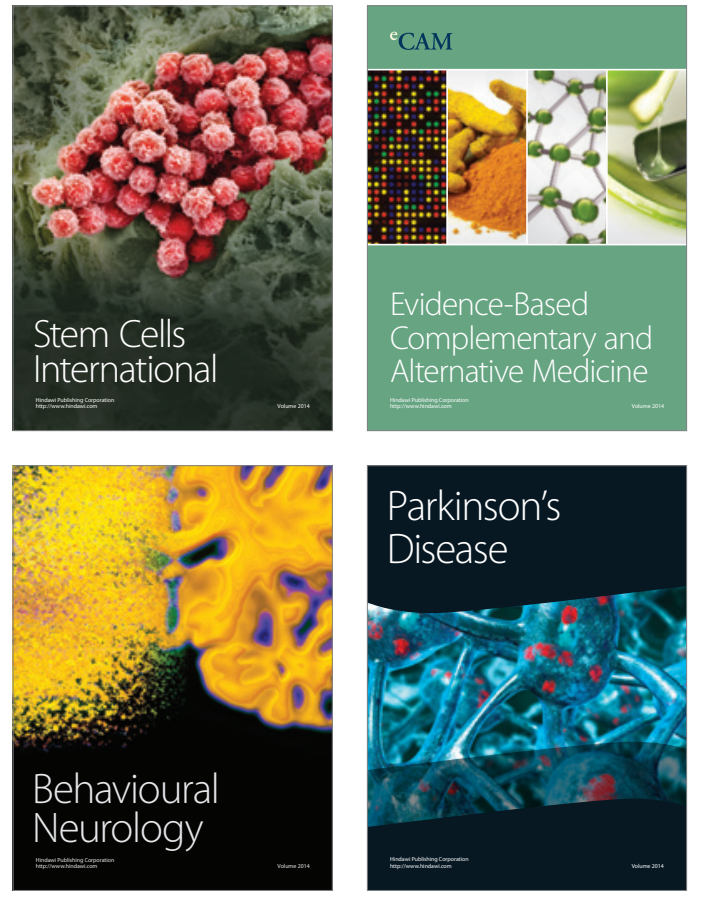
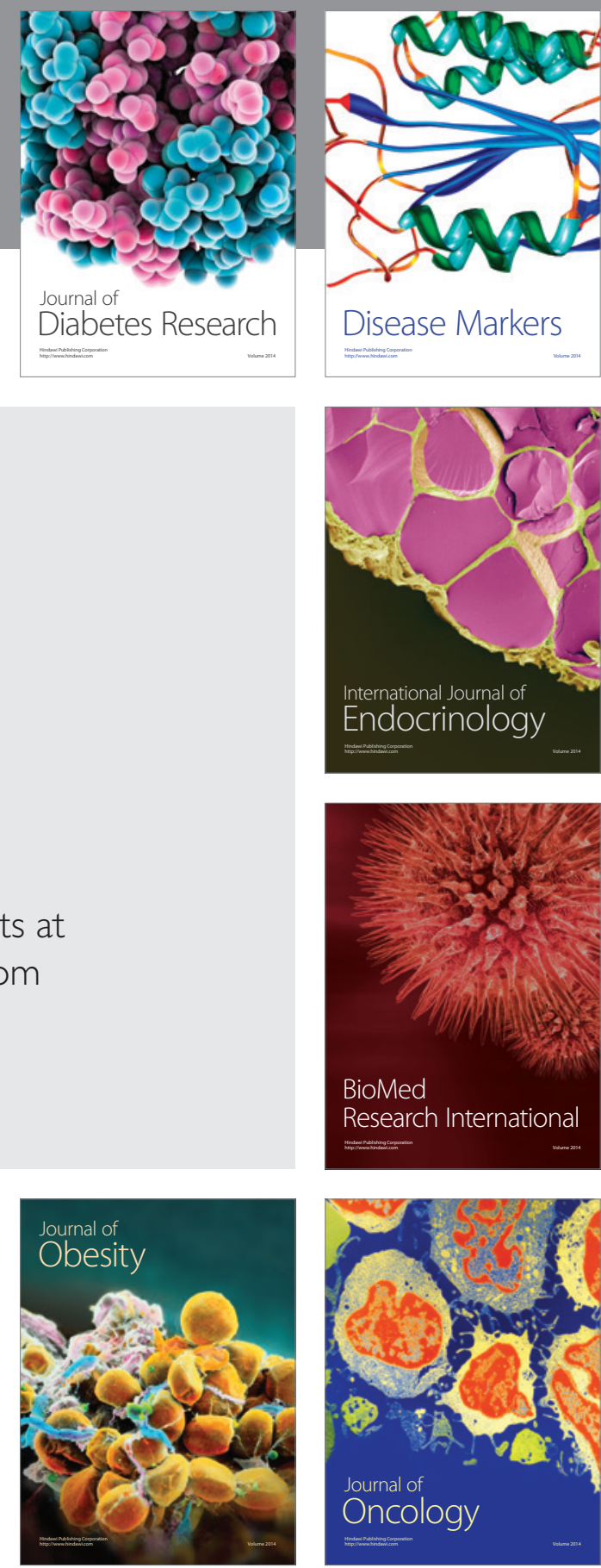

Disease Markers
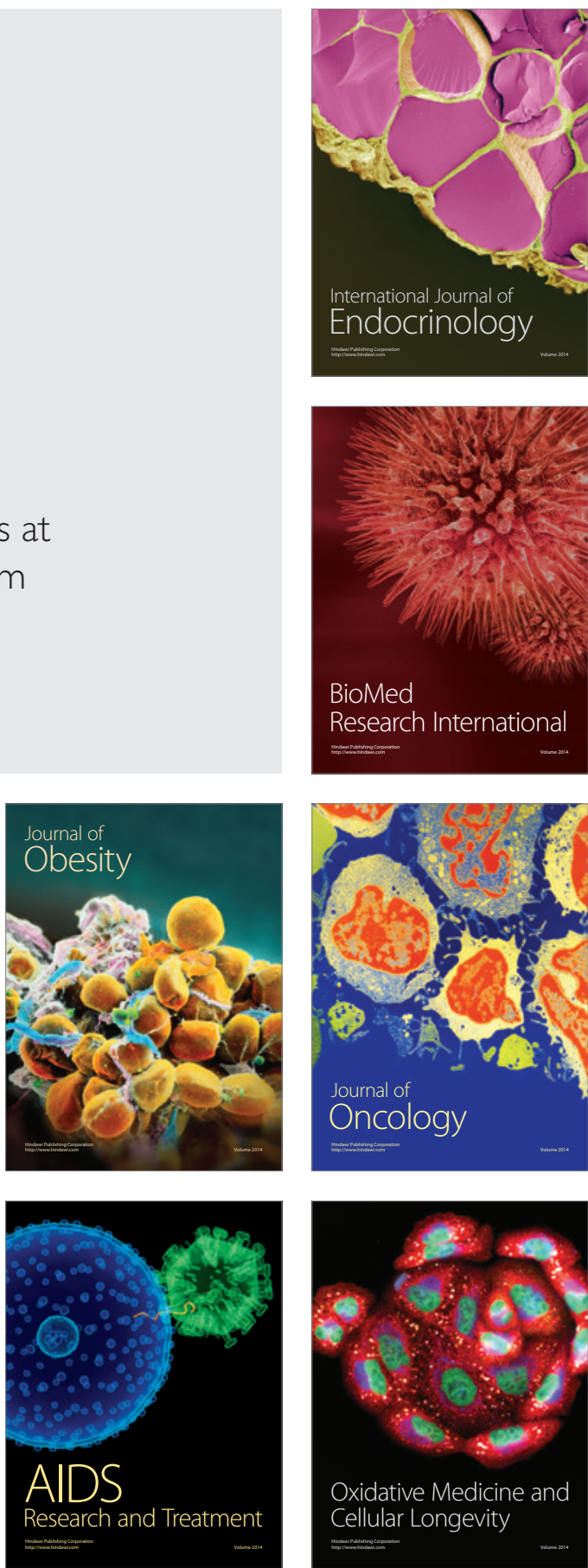